\title{
Academic Staffs' Level of Organizational Commitment in Higher Educational Setting: The Case of Haramaya University
}

\author{
Endris Seid Kassaw ${ }^{1}$ (M.A.) \& Dawit Negassa Golga ${ }^{2}$ (PhD.) \\ ${ }^{1}$ Social Psychology, Haramaya University, Ethiopia \\ ${ }^{2}$ Special Needs and Inclusive Education, Haramaya University, Ethiopia \\ Correspondence: Endris Seid Kassaw (M.A.), Social Psychology, Haramaya University, Ethiopia
}

Received: April 1, 2019

Accepted: April 21, 2019

Online Published: April 22, 2019

doi:10.5430/ijhe.v8n2p87

URL: https://doi.org/10.5430/ijhe.v8n2p87

\begin{abstract}
Employees' organizational commitment is considered as a crucial issue in higher education setting for realizing institutional vision, attaining its goals, and uplifting employees' motivation to achieve better work performance. This subject has, therefore, been studied so as to draw attention to enhance the effectiveness of Ethiopian higher education institutions with particular reference to Haramaya University. Thus, the main objective of this study was to assess academic staffs' level of organizational commitment. In addition, the study assessed whether there exist a significant difference in academic staffs' level of organizational commitment in terms of their gender and level of education. A cross-sectional research design was employed in the study. Primary and secondary data sources were used. A commitment scale questionnaire was used to collect data from 275 participants who were selected using stratified random sampling technique as well as further information about the study were also collected using focus group discussion and document review. The quantitative data were analyzed using both descriptive and inferential statistics; the qualitative data were analyzed using content and narration methods of data analysis. The study revealed that academic staffs of the university have moderate level of organizational commitment. With this level of organizational commitment, it is less likely to attain both individual work performance objectives and organizational missions and vision of the university. In addition, there were relative implications of turnover, turnover intention, absenteeism, and demotivation among academic staffs. The study further revealed that although there is no significant difference in level of commitment with reference to gender, academic staffs' level of organizational commitment was significantly different with reference to their level of education. Thus, it is recommended that the working environment of the university is revisited by giving due emphasis to and addressing the determinants that lower the organizational commitment of the staff.
\end{abstract}

Keywords: academic staff, gender, level of education, organizational commitment

\section{Introduction}

\subsection{Background of the Study}

Organizational commitment can be attitude and behavior (SamGnanakkan, 2010) resulted from the assessment of employees work situations which attached them with their organizational values and goals. According to Jans (1989), it is related to what extent the acceptance, internalization and perception of organizational goals by employees. The same explanation is given in Mowday, Porter and Steers in (1982) and Ogaboh, Nkpoyen and Ushie in (2010) that organizational commitment is related to employees identification with, provide extra effort on behalf of the organization and desire to be member of the organization for its effectiveness.

The ideas on organizational commitment by Meyer and Allen in (1990), Viljoen and Rothmann in (2009). Yusuf and Metiboba in (2012) Lamba and Choudhary in (2013) similarly dealt with as it is a psychological state that employees are concerned with relationship, membership, fillings of obligation and loyalty for the contribution of organizational welfare and work performance.

Allen and Meyer (1990) as well as Samad (2011) clearly indicated that the three dimensions of organizational comment (affective, continuance and normative) link together to explain the psychological state/behavior of employees in their emotion or feeling of involvement, relationship and membership to the organization, in their decision for awareness of costs associated with stay or leave the organization as well as in feeling of obligation and loyalty to continue in employment because it is the right and moral thing to do for perceived support, inducements or 
incentives.

Allen \& Meyer (1991), Curtis and Wright (2001), Stallworth (2004) Madsen, Miller and John (2005), Yiing and Ahmad (2009), as well as Cunningham (2012) similarly indicated that if employees of the organization have a robust affective commitment, they will stay in the organization because they want to for whom individual characteristics (most of the time demographic feature), work experiences like job challenge, organizational support, role clarity, transformational leadership, empowerment, and job importance, are the attributes their commitment.

In the case of strong continuance commitment, employees of the organization will stay due to they need to do so on the bases of individuals' perception or weighing of costs and risks associated with leaving the current institution or lack of job alternatives. Normative commitment is associated with employees feeling of obligation and loyalty for their organization or a sense of guilt feeling about the possibility of leaving based on the perceived supports and encouragements like training, education and personal development.

It is a fact that the commitment of employees determines the performance and success of organizations (Fiorita, Bozeman, Young \& Meurs, 2007 and Brown \& Sargeant, 2007). For example, work performance and success become at risk where the employees' organizational behavior such as commitment is poor to undertake various responsibilities and tasks.

In addition, as of Huselid (1995), Bin, Ahmed, Shafi and Shaheen (2011) as well as Solomon, Hashim, Mehdi and Ajagbe (2012) strong commitment of employees leads to effectiveness of organizational work performance and success, increased organizational wellbeing, employees motivation, organizational citizenship behavior, good work culture and improved individuals' job performance. It also helps for decrease of employees' behaviors and practice of turnover, turnover intentions, absenteeism, sabotage, as well as the absence of institutional failure.

Awareness about the employees' level of organizational commitment must be a pivotal issue for any institution because it is the human factor that mobilizes other resources for effective work performance and success. Commitment of staff is a socio-psychological state which is attributed in their attachment to the institution; and has implications in their decision to stay in it (Yusuf \& Metiboba, 2012).

Thus, organizational commitment of academic staff entails their readiness to the acceptance of visions, goals and values of the institution; be loyal and exert extra effort and stand for on behalf of the university and willingness to continue membership with it. It was explained that employees with strong commitment need to stay and positively support the institution (Welty, Burton \& Wells, 2014).

Although much effort were made to have improved work performance in Ethiopian higher education institutions, particularly in the context of Haramaya University, little emphasis was provided to what extent the status of staffs' organizational commitment is valuable for both individual and institutional effectiveness.

Thus, academic staffs' level of organizational commitment in higher educational setting requires due attention of researchers particularly with reference to Haramaya University.

\subsection{Statement of the Problem}

The transformation of work performances in higher education institutions, for example, like transformation in student learning, designing new methodology of teaching, technology transfer, research work, community services, produce civilized society and build nations, etc seeks strong commitment of academic staffs.

Literatures support the view that higher education is a labor intensive activity and seeks strong organizational performance in exploiting the rest of resources depending on its staffs' commitment.

According to the ideas of Chartered Institute of Personnel and Development (2014) and Altbach (2006), higher education institutions cannot maintain and ensure their success in terms of long and short term visions, values and goals through sustainable work performance unless they improve their staffs' commitment and qualification. Committed staffs have high motivation for learning, new work strategies, extra effort to develop skills, have willingness to challenge, experiment new ways and principles of work, developed improved citizenship behaviors to the institution and work culture, by all of which universities effectiveness and quality work performances are ultimately insured (Jafri, 2010 and Iliya \& Ifeoma (2015).

However, Oludeyi (2015) explored that academic staffs' intellectual capital, creative abilities and commitment determine the success of universities in various issues, like responsibility to teach, undertake problem-solving research, community services and good governance.

The evidence presented thus far leads to have an understanding and a belief that staffs' organizational commitment is 
compulsory and irreplaceable because without employees' commitment, it will be deceptive and a dream to use technology and system as well as to attain institutional vision, values and goals.

Researchers Salami and Omole (2005) have disclosed that organizational commitment is a function of several variables like, motivation, participative decision making, support, financial reward, communication, promotion prospects and leadership styles. According to Brown and Sargeant (2007), there are several factors like job expectations, physiological contracts and personal characteristics (gender, marital status, seniority, position, education, race, and social culture) which influence staffs' level of organizational commitment.

In addition, Riggio (2009) explained that organizational commitment is most commonly affected by type and variety of work, the autonomy involved in the job, the level of responsibility associated with the job, the quality of social relationship at work, rewards and remunerations, and the opportunities for promotion and career advancements in the institution.

In the context of Ethiopia, some studies like Tesfaye (2004) asserts that organizational commitment, particularly the affective dimension, has been significantly predicted by salary adequacy, and perceived quality of leader. Whatever various factors that influence them, Tekle and Solomon (2016) indicated that staffs' job satisfaction and organizational commitment are influential factors for improving the quality of education, teachers' occupational success and improved students' learning etc. In their study, it was also indicated that there were difference among commitment dimensions and they assured that academic staffs have more affective commitment than normative commitment and continuance commitment respectively at Arbaminch University; whereas Alemu (2014), generally, indicated that academic staffs have moderate level of organizational commitment in case of Adama Science and Technology University.

However, although some researches were conducted on employees' commitment in the context of Ethiopian organizations, there was no much sound evidence on assessment of staffs' level of organizational commitment particularly in higher educational setting. Thus, employees' organizational commitment has been still one of the pressing issues in many higher education institutions of Ethiopia which, however, has not yet been well addressed.

Therefore, the researchers were initiated to take part in filling such a gap through focusing their investigation on assessment of academic staffs' level of organizational commitment in Haramaya University and the following basic research questions were raised.

\subsection{Basic Research Questions}

1. What is the level of academic staffs' organizational commitment in terms of the three dimensions of commitment (affective, continuance and normative)?

2. Is there significant gender difference among academic staffs' in terms of the three organizational commitment dimensions?

3. Does the level of education attained by the academic staff significantly contribute to their level of organizational commitment?

\subsection{Purpose of the Study}

The main objective of this study was to assess academic staffs' level of organizational commitment in Haramaya University. The study also included the following specific objectives.

1. Identify whether there was a significant difference in academic staffs' level of organizational commitment in reference to their gender.

2. Know whether academic staffs' level of education had a significant contribution in their level of organizational commitment.

\section{Research Design and Methods}

The purpose of the study was to assess academic staffs' level of organizational commitment and ascertain whether a significant difference exists in the level of organizational commitment with respect to gender and level of education.

A cross-sectional research design was used to examine the phenomenon and major related variables because such a design enables to generate data from a large number of participants concerning the issue at one point and time. The design is also appropriate for the study as it allows entertaining both the descriptive and predictive functions. Thus, different levels of participants' organizational commitments were examined using variables of gender and level of education to study the differences among the groups in organizational commitment among academic staffs 
Thus, organizational commitment of participants with different background characteristics was examined using variables of gender as well as level of education as displayed in table 1.

Table 1. Demographic Characteristics

\begin{tabular}{ll}
\hline Demographic Characteristics & Measured Variable \\
\hline Gender with two groups & Organizational commitment \\
- & \\
- & Female \\
Level of education with three groups & \\
- Bachelor of Arts or Science Degree (B.A/ Sc,) & \\
- Masters of Arts or Science Degree (M.A/ Sc.) & \\
- Assistance Professors plus Philosophy of Degree and above \\
$\quad$ (Ass.Prof./PhD. \& above)
\end{tabular}

\subsection{Sources of Data}

The primary data sources were participants of the study and the sources of secondary data were also reviewed documents like journals, reports and related credentials.

\subsection{Population, Sample and Sampling Techniques}

The population of the study was academic staffs of Haramaya University who are 1254 in number. All staff members on duty $\mathrm{N}=877$ were considered as target population of the study and academic staff on study leave were excluded based on the list generated from the Human Resource Management Directorate of the University.

This is because the focus of the study was to investigate the extent to which academic staffs on duty were committed for their actual job and for realization of institutional vision. The study further aimed to know whether there is a significant difference in organizational commitment in terms of gender and level of education. Thus, both male and female participants were included in the study. Academic staffs were classified into 3 strata based on their level of education as (BA/BSc, MA/MSc, and $\mathrm{PhD} \&$ above); and the sample was selected proportionately from each stratum by using stratified random sampling technique.

Researchers used Slovin's formula which was developed by Yamane (1964) to determine participants' sample size in the study. Slovin's formula: $\left[\left(\mathrm{n}=\mathrm{N} \div\left(1+\mathrm{NE}^{2}\right)\right]\right.$ Where: $\mathrm{N}=$ total population; $\mathrm{n}=$ sample size, $\mathrm{E}=$ =error rate/margin of error (.05) or that the chance of samples to be representative of the population is 95 percent confidence level. Thus, the sample size of this study was calculated as $n=877 / 1+877 *(0.05 * 0.05)=275$.

Table 2. Stratified Sampling Frame

\begin{tabular}{|c|c|c|c|c|}
\hline \multirow[t]{2}{*}{ Strata } & & & & \\
\hline & B.A/ Sc. & M.A/ Sc. & Ass.Prof./PhD. \& above & Total \\
\hline Population Size & 172 & 553 & 152 & 877 \\
\hline Sample Size & 54 & 173 & 48 & 275 \\
\hline
\end{tabular}

The Sample size for each stratum was determined by using the following equation: $n h=(\mathrm{Nh} / \mathrm{N}) \times \mathrm{n}^{*}$, where, $\mathrm{nh}=$ sample size for stratum $\mathrm{h}, \mathrm{Nh}=$ population size for stratum $\mathrm{h}, \mathrm{N}=$ total population size, $\mathrm{n}^{*}=$ total sample size. Researchers also purposively select 5 individuals from deferent academic units to be participant in focus group discussion for further information about the study

\subsection{Data Collection Instruments and Procedures}

Researchers used questionnaire, focus group discussion and document review. The questionnaire was written in English and had two parts. The first part focused on seeking information on participants' socio-demographic variables and the second part focused on scale items dealt with the measure of academic staffs' level of organizational commitment.

The scale questionnaire totally comprised of 20 items and had in part measurement of three dis-aggregated dimensions of organizational commitment. Items were prepared with a five point Likert type scale responses to be rated ranging from strongly agree $(=5)$ to strongly disagree $(=1)$. This scale was adopted from the revised scale of enhanced model for the measurement of organizational commitment (Meyer \& Allen, 1997 as cited in Stephen J, 
2007) with little modification only.

Researchers, and experts who were instructors in the university and who have been specialized in disciplines of educational psychology, social psychology and management, were invited for their solicited expert opinions to examine the content validity of the questionnaire. The opinion of both researchers and experts reflected that no items need to be discarded except little modification.

Then after, researchers checked reliability of items in terms of internal consistency using the Cronbach Alpha level; thus, the overall organizational commitment items scale's alpha was measured 0.79.

In part, items for each of the three disaggregated organizational commitment dimensions were measured to have an alpha level of 0.87 for affective commitment, 0.79 for continuance commitment and 0.72 for normative commitment. All these alpha value measures were acceptable to use for the study. This is because Nunnally and Bernstein (1994) clearly indicated that a Cronbach alpha coefficient of 0.70 and above is an acceptable level of internal consistency.

Partly eight items in the scale were seeking to measure the affective commitment dimension using items like "I enjoy discussing about my University with people outside it", "I am very happy being a member of this University "etc.; six items dealt to measure continuance commitment dimension using items like "Worry about the loss of investments I have made in this University" , "If I wasn't a member of this University, I would be sad because my life would be disrupted" etc.; and the rest six items focused on measurement of normative commitment dimension using items like "I feel that I owe this University quite a bit because of what it has done for me", "My University deserves my loyalty because of its treatment towards me"etc.

Thus, the questionnaire was distributed for 275 participants from which $242(88 \%)$ were properly filled and returned. Then, scores of four Negatively- keyed items ("I think that I could easily become as attached to another University as I am to this one; I do not feel like 'part of the family' at my University; I do not feel 'emotionally attached' to this University; and I do not feel a 'strong' sense of belonging to my University.") in the affective commitment dimension as well as one item ("Sometimes I worry about what might happen if something was to happen to this University and I was no longer a member.") in the continuance commitment dimension, were reversed as per the scale manual of scoring.

Some document review and focused group discussion were conducted to triangulate the data and to have further information relating to factors that determine academic staffs' level of organizational commitment in higher education.

\subsection{Method of Data Analysis}

Researchers used both quantitative and qualitative methods of data analysis. Particularly, frequency distribution to summarize participants' demographic variables, and averages to assess participants' level of organizational commitment were used. And thus, the rage of average scores of academic staffs' level of organizational commitment were described as $1-2.49$ to be interpreted as "low level", $2.5-3.49$ to be interpreted as "moderate level" and $3.5-5$ to be interpreted as "high level".

In addition, Independent sample T-test was used to see whether a difference was existed in level of organizational commitment with reference to gender. The MANOVA and ANOVA tests were also used to see whether level of education had a significant contribution to level of organizational commitment. The statistical software (SPSS version 23) was used to run quantitative analysis. Content and narration methods of analysis were used for analysis of qualitative data.

For analysis of qualitative data collected through document review and focus group discussion, researchers used combination of content and narration methods of data analysis.

\subsection{Ethical Considerations}

The following ethical considerations were taken into consideration in addition to the granted permission by the Department of Psychology at Haramaya University.

1. Participants' dignity and privacy were protected by making them free from any physical and verbal abuse

2. The researchers firstly obtained participants' full permission orally to participate in the study while taking samples.

3. The researchers were responsible and highly sensitive in keeping participants' confidentiality during or after investigation in that information and recorded evidences are secured and/or protected. 


\section{Results}

\subsection{Demographic Characteristics of Academic Staffs}

Participants' demographic characteristics have provided basic information about their distribution based on gender and level of education.

Table 3. Demographic Characteristic of Participants

\begin{tabular}{clll}
\hline Gender & & Frequency & \% \\
\hline Female & 70 & 28.90 \\
Male & 172 & 71.10 \\
& Total & 242 & 100.0 \\
\hline Level of Education & Frequency & $\%$ \\
\hline B.A/ BSc. holder & 37 & 15.30 \\
M.A / MSc. holder & 160 & 66.10 \\
Assi. Prof /PhD. \& above & 45 & 18.60 \\
Total & 242 & 100.00
\end{tabular}

As shown in Table 3, for gender distribution, there was more percentage of male participants compared to their female counterparts. Concerning the level of education, as shown in the same table, it can be seen that a great majority of the study participants had MA or MSc degree followed by participants with the rank of assistant professor or doctor of philosophy and above. Participants in the lowest percentage had Bachelor of Arts / Bachelor of Science degree. This finding indicates that yet there was relatively small number of female academic staff in the university despite affirmative actions taken to balance the proportion in terms of gender. Most of the study participants were found to be MA or MSc degree holders though the required proportion between MA/MSC and PhD holders should be 60:40 respectively.

\subsection{Academic Staffs' Level of Organizational Commitment}

Table 4 shows that majority of the academic staff s had moderate level of overall organizational commitment (Mean $=3.24,=$ Standard deviation $=0.55)$ though there were values indicating both minimum (1.35) and maximum (4.75) level of organizational commitment. Furthermore, the same Table displays levels of the three disaggregated organizational commitment dimensions in terms of average and standard deviation with their minimum and maximum values.

Table 4. Academic Staffs' Level of Organizational Commitment

\begin{tabular}{llllll}
\hline & $\mathrm{N}$ & Minimum & Maximum & Mean & Std. Deviation \\
\hline Affective commitment & 242 & 1.38 & 5.00 & 3.4396 & .91298 \\
Normative commitment & 242 & 1.00 & 5.00 & 3.3072 & .74273 \\
Continuance Commitment & 242 & 1.00 & 5.00 & 2.9167 & .88156 \\
Overall Commitment & 242 & 1.35 & 4.75 & 3.2430 & .55125
\end{tabular}

Table 4, depicts that the mean score for affective commitment is 3.44 (standard deviation $=0.91$ ), which is greater than the mean score for normative commitment (mean $=3.31$, standard deviation $=0.74$ ) which in turn is greater than the mean score for continuance commitment (mean $=2.91$, standard deviation $=0.88$ ).

Thus, the largest mean score belongs to the affective commitment; whereas the lowest mean score belongs to the continuance commitment followed by the mean score for overall organizational commitment. Although there seems to be difference in mean and standard deviation values among the three dis-aggregated levels of commitment, all lie in the same range of moderate level.

This means that the commitment of the academic staff is at moderate level with respect to the three dis-aggregated commitment dimensions listed as affective, continuance and normative commitments.

From the focus group discussion, it was found that most of the academic staffs did not perform their task to the required level or expertise by putting extra effort due to different factors. In relation to this, one study participant in 
the focus group discussion, for example, explained that $I$ don't have the feeling to do more and continue to be a member of the university in such a toxic and unhealthy work environment. The participant added that

Frequent disturbance and conflict among students for personal reasons and national political issues, lack of concern from the management body for the wellbeing and interest of staff, along with lack of proper incentive for work done made me anxious to stay in the institution. So I resort to leave. (Excerpt from male participant).

The other study participant, however, mentioned that there were conditions that encourage him to do more, particularly when incentives were arranged, respect and encouragements or supports were provided but that it doesn't necessarily mean that he is loyal to the institution. He further strengthened his views by saying that he could do more for the institution so long as it is followed by extra payment and moral support.

Thus, this gives an indication that the level of commitment can be determined by different factors such as work environment, organizational culture, the performance of leaders to solve the problem, incentives and support. From review of relevant documents and participants' focus group discussion, it was found that possible determining factors for academic staff level of organizational commitment include leadership behavior (the qualities, traits and behavior of the leaders), lack of proper incentives, acknowledgment and compensation, work environment, personal characteristics like perceptions and self-esteem behaviors, personality, shortage of capacity building training, task orientation, organizational justice, lack of accessible facility, feelings, interest, nature of work, low attitude and motivation.

It was also ascertained from the focus group discussion that factors like intelligence, creativity; relationship with colleague, trustworthiness, loyalty, insecure political condition of the country and senses of ownership to the organization significantly determines the organizational level of academic staff commitment. For example, one participant in the focus group discussion explained that if a staff member acquires high emotional intelligence and motivation, it is expected to he/she exhibits high commitment. However I have no observation of a staff that has good motivation, willingness and emotional management in our case. Emphasizing how personality and attitude determine the level of academic staff organizational commitment, the other participant in the focus group discussion said that $a$ positive attitude should be built and initiative should be taken when someone involves in accomplishing a certain task effectively. Thus, attitude and personality were factors considered to have influence on commitment.

It was further explained in the focus group discussion that although leaders who demonstrate concern about staff well-being, responsible, responsive and eager to organizational change can initiate employees to put an extra effort for the effective institutional work performance and loyal to be membership to the organization it was less likely observed in the context of Haramaya University. In some reviewed documents it was clearly evidenced that when employees, particularly academic staff are motivated, they show the need for and interest to perform in the best way possible with respect to their task and will therefore demonstrate an increased level of organizational commitment.

\subsection{Gender Difference in Academic Staff Level of Organizational Commitment}

Independent t-test was computed to examine whether there is a significant difference in academic staff level of organizational commitment with reference to gender.

To this end, four independent t-tests were computed generally to see differences between male and female participants in their overall commitment and in three dis-aggregated commitment dimensions; the four t-test results were summarized and presented in table 5.

Table 5. Group Statistic and Independent T-Test

\begin{tabular}{|c|c|c|c|c|c|c|c|c|c|}
\hline \multicolumn{10}{|l|}{ Group statistics by Gender } \\
\hline & \multicolumn{2}{|c|}{ Female $(\mathrm{N}=70)$} & \multicolumn{2}{|c|}{ Male $(\mathrm{N}=172)$} & \multicolumn{5}{|c|}{ Independent Sample t-test } \\
\hline & Mean & SD & Mean & SD & $\mathrm{F}$ & Sig. & $\mathrm{T}$ & $\overline{\mathrm{Df}}$ & $\mathrm{P}$ \\
\hline Affective Commitment & 3.48 & .936 & 3.42 & .906 & .948 & .331 & .481 & 240 & .631 \\
\hline Continuance Commitment & 2.96 & 1.023 & 2.90 & .8120 & 7.883 & .005 & .464 & 107 & .644 \\
\hline Normative Commitment & 3.44 & .751 & 3.25 & .735 & .046 & .830 & 1.789 & 240 & .075 \\
\hline Overall Commitment & 3.31 & .531 & 3.21 & .559 & .193 & .661 & 1.286 & 240 & .200 \\
\hline
\end{tabular}

Concerning the level of affective commitment, as shown in table 5, there was no significant difference between female $($ Mean $=3.48$, standard deviation $=0.94)$ and male study participants $($ Mean $=3.42$, standard deviation $=$ $0.91) ; \mathrm{t}(240)=0.48, \mathrm{P}=0.63$. The same table shows that there was no significant difference in continuance 
commitment between female $($ Mean $=2.96$, standard deviation $=1.02)$ and male $($ Mean $=2.90$, standard deviation $=0.81) ; \mathrm{t}(107)=0.46, \mathrm{P}=0.64$. In addition, table 5 indicates that female academic staff scored $($ Mean $=3.44$, Standard deviation $=0.75)$ slightly greater than male academic staff $($ Mean $=3.25$, Standard deviation $=0.74)$. However, the difference was not statistically significant; $\mathrm{t}(240)=1.79, \mathrm{P}=0.075$.

When overall organizational commitment of academic staff is considered, table 5 displays that there is no significant difference between female $($ Mean $=3.31$, Standard deviation $=0.53)$ and male $($ Mean $=3.21$, Standard deviation $=$ $0.54) ; \mathrm{t}(240)=1.29, \mathrm{P}=0.200$. Thus, all the test results suggest that gender has no effect on the level of academic staff organizational commitment.

\subsection{Differences in Organizational Commitment with Reference to Level of Education}

In order to assess whether level of organizational commitment is significantly different among academic staff in terms of their level of education, two tests namely one-way multiple analysis of variance (MANOVA and one-way analysis of variance (ANOVA) were computed.

One-way MANOVA test was used to see the difference among groups in contribution of level of education on each of the three dis-aggregated commitment dimensions as a unit; whereas one-way ANOVA was used to see whether there is difference in academic staffs' overall organizational commitment in their level of education.

Thus, it is assumed that the null hypothesis for the one-way MANOVA measure was the mean score for three groups in level of education are equal in analysis of the difference in three commitment dimensions (affective, continuance and normative).

Table 6. Descriptive Statistics of Variables used for MANOVA

\begin{tabular}{llllllll}
\hline & \multicolumn{3}{c}{ Affective } & \multicolumn{3}{c}{ Continuance } & \multicolumn{2}{l}{ Normative } \\
\cline { 2 - 8 } Level of Education & $\mathrm{N}$ & Mean & $\mathrm{SD}$ & Mean & SD & Mean & SD \\
B.A/ Sc. Holder & 37 & 3.76 & .824 & 2.97 & .928 & 3.52 & .644 \\
M.A / Sc. Holder & 160 & 3.37 & .935 & 2.91 & .896 & 3.24 & .751 \\
Assistant Prof /PhD. \& above & 45 & 3.41 & .863 & 2.90 & .804 & 3.38 & .762 \\
Total & 242 & 3.44 & .913 & 2.92 & .882 & 3.31 & .743 \\
\hline
\end{tabular}

Table 6 gives a preliminary information that there was only a slight difference in distribution of scores in mean average and scores of standard deviation among groups in participants' level of education across each commitment dimensions (affective, continuance and normative).

Academic staff holding M.A / MSc. degree had the lowest value for affective commitment (Mean $=3.37$, standard deviation $=0.94)$ and in normative commitment $($ Mean $=3.24$, standard deviation $=0.75)$ among groups found in each of the three dis-aggregated organizational commitment dimensions. Whereas B.A / BSc. holders had the highest value in all the dimensions of commitment; affective (Mean $=3.37$, standard deviation $=0.94)$, continuance $($ Mean $=$ 2.97, standard deviation $=0.94)$ and normative $($ Mean $=3.52$, standard deviation $=0.64)$ among groups found in each of the three dis-aggregated organizational commitment.

A one-way MANOVA was computed to see whether significant difference exists in the three dis-aggregated commitment dimensions across groups with different levels of education.

The results from SPSS version 23 was shown in Table 7. For this study, Wilks' Lambda test result was computed among other statistical test results due to its wide usage and advisability as an appropriate multivariate test statistics especially when such a test is not significant. In this study, test of equality of covariance matrices was taken into consideration using $\mathrm{P}<0.05$ as a criterion for level of significant. Then the test result showed a Box's M (0.829); from which it was possible to confirm that the test is not significant, p $(0.829)>0.05$. Thus, Wilk's Lambda was confirmed to be used as an appropriate test. 
Table 7. MANOVA Results (Modified from SPSS Output)

\begin{tabular}{llccccccc}
\hline \multirow{2}{*}{ Effect } & Test Statistics & Value & F & $\begin{array}{c}\text { Hypothes } \\
\text { is df }\end{array}$ & Error df & Sig. (p) & $\begin{array}{c}\text { Partial } \\
\eta 2\end{array}$ & $\begin{array}{c}\text { Noncent. } \\
\text { Parameter }\end{array}$ \\
\hline Level of Education & Pillai's Trace & .036 & 1.45 & 6 & 476 & .196 & .018 & 8.670 \\
& Wilks' Lambda & .964 & $1.45^{\mathrm{b}}$ & 6 & 474 & .194 & .018 & 8.689 \\
& Hotelling's Trace & .037 & 1.45 & 6 & 472 & .193 & .018 & 8.708 \\
& Roy's Largest Root & .034 & $2.69^{\mathrm{c}}$ & 3 & 238 & .047 & .033 & 8.078 \\
\hline
\end{tabular}

As it is displayed in table 7, one-way multiple analysis of variance test was computed and its result showed that there is no statistical evidence to support difference among groups in each of the three dis-aggregated commitment dimensions with reference to their level of education; $\mathrm{F}(6,474)=1.45, \mathrm{P}=0.19$, Wilks' $\mathrm{A}=0.96$; a multivariate $\eta 2$ $=0.018$. The multivariate result $\eta 2=0.018$ indicates the level of education had little (2\%) contribution on commitment dimensions.

Since the result of the MANOVA test was not significant to retain the null hypothesis, there was no need to carry out the follow-up analysis to find out where the significant difference existed. Whereas the null hypothesis for ANOVA measure was that the mean score for three groups in level of education are equal in analysis of the difference in level of overall commitment.

Table 8 shows descriptive statistics and tests of between-subjects effects in one-way ANOVA test for the variables of the data used for this test in the study.

Table 8. Descriptive Statistics and Tests of Between-Subjects Effects in Overall Organizational Commitment

\begin{tabular}{|c|c|c|c|c|c|c|c|}
\hline \multicolumn{8}{|l|}{ Descriptive Statistics } \\
\hline Level of Education & & \multicolumn{2}{|c|}{$\mathrm{N}$} & \multicolumn{2}{|c|}{ Mean } & \multicolumn{2}{|c|}{ Std. Deviation } \\
\hline B.A / Sc. Holder & & \multicolumn{2}{|c|}{37} & \multicolumn{2}{|c|}{3.4527} & \multicolumn{2}{|l|}{.48662} \\
\hline M.A / Sc. Holder & & \multicolumn{2}{|c|}{160} & \multicolumn{2}{|c|}{3.1934} & \multicolumn{2}{|l|}{.56153} \\
\hline Assistant Prof /PhD. \& above & & \multicolumn{2}{|c|}{45} & \multicolumn{2}{|c|}{3.2467} & \multicolumn{2}{|l|}{.53411} \\
\hline Total & & \multicolumn{2}{|c|}{242} & \multicolumn{2}{|c|}{3.2430} & \multicolumn{2}{|l|}{.55125} \\
\hline \multicolumn{8}{|l|}{ Between Subjects } \\
\hline Source & Sum Sqr & df & Mean Sqr & $\mathrm{F}$ & Sig. & Partial $\eta 2$ & Noncent. \\
\hline Level of Education & 2.021 & 2 & 1.010 & 3.391 & .035 & .028 & 6.782 \\
\hline Error & 71.212 & 239 & .298 & & & & \\
\hline Total & 2618.320 & 242 & & & & & \\
\hline
\end{tabular}

A between groups analysis of variance test was computed to see the contribution of level of education in overall organizational commitment scores. In this test, there were three groups of participants with level of education described as B.A /BSc. holder, M.A / MSc. holder and Assi. Prof /PhD. \& above. The test result showed that there was statistically significant difference among such groups of participants' overall organizational commitment scores $\mathrm{F}(2,239)=3.39, \mathrm{P}=0.035$. Although the observation of test reached statistical significance, the difference in mean scores between groups was actually quite small.

This can be observed in effect size at partial eta squared ( $\eta 2)$ that was 0.028 . In order to identify which particular group caused for the significant difference in this study, a multiple or post-hoc comparisons using the Tukey HSD significant difference criteria was computed and the result is displayed in table 9. 
Table 9. Multiple Comparisons of Groups for Differences in Overall Organizational Commitment

\begin{tabular}{llccccc}
\hline & & & & & \multicolumn{2}{c}{$95 \%$ Confidence } \\
\cline { 5 - 7 } (I) Level of Education & (J) Level of Education & Mean Diff (I-J) & Std. Er & Sig. & Lower & Upper \\
\hline B.A / Sc. Holder & M.A / Sc. Holder & $.2593^{*}$ & .09958 & .026 & .0244 & .4941 \\
& Assi. Prof /PhD.\& above & .2060 & .12114 & .207 & -.0797 & .4917 \\
M.A / Sc. Holder & B.A / Sc. Holder & $-.2593^{*}$ & .09958 & .026 & -.4941 & -.0244 \\
& Assi. Prof /PhD.\& above & -.0532 & .09211 & .832 & -.2705 & .1640 \\
Assi.Prof /PhD.\& above & B.A / Sc. Holder & -.2060 & .12114 & .207 & -.4917 & .0797 \\
& M.A / Sc. Holder & .0532 & .09211 & .832 & -.1640 & .2705 \\
\hline
\end{tabular}

Post-hoc comparisons of Tukey HSD test showed that there was significantly greater score for B.A / BSc. holders $($ Mean $=3.45$, standard deviation $=0.49)$ than M.A $/$ MSc. holders $($ Mean $=3.19$, standard deviation= 0.56 $)$; $\mathrm{P}=0.026$. The same table shows that there was no statistically significant difference in mean scores between B.A $/$ BSc. holders $($ Mean $=3.45$, standard deviation $=0.49)$ and Assi. Prof $/ \mathrm{PhD}$. and above $($ Mean $=3.25$, standard deviation $=0.53) ; \mathrm{P}=0.207$.

Table 9 also reveals that there was no statistically significant difference in mean scores between M.A / MSc. holders $($ Mean $=3.19$, Standard deviation $=0.56)$ and Assi.Prof $/ \mathrm{PhD} . \&$ above, $($ Mean $=3.25$, Standard deviation $=0.53) ; \mathrm{P}$ $=0.832$.

\section{Discussion}

\subsection{Demographic Characteristics of Academic Staffs}

The frequency distribution gives a clear overview of the type of respondents. Thus, all participants of the study were academic staff and their gender and level of education were considered as the demographic variables. With respect to gender, there were more male (71\%) than female (29\%) staff members to participate in the study which sought to investigate their level of organizational commitment towards realizing the vision and missions of the university.

Though the distribution among participants in terms of gender seems unequal due to the small number of females, the sample was taken through considering and balancing their availability in the university particularly in their level of education. In the context of Ethiopian higher education that favors female academic staff, the finding reflects that still there were relatively small number of female academic staff though attempts were made to balance the proportion of gender in the recruitment of the academic staff.

With reference to participants' education, there were bachelor of arts/sciences degree holders (15\%); masters of arts/science degree holders (66\%) and assistant professors or doctor of philosophy degree holders \& above (19\%). The lowest percentage of participants was found in an educational level of Bachelor of Arts/ Bachelor of Science degree. This is due to their availability in relatively small number in the University despite the expectation in Ethiopian higher education institutions to have $0 \%$ academic staff with bachelor's degree. Thus, the researchers balanced their proportion in the sample by using stratified random sampling technique.

\subsection{Academic Staffs' Level of Organizational Commitment (Affective, Continuance and Normative)}

This study assessed the level of organizational commitment among academic staffs in Haramya University. This was due to the fact that the success of the university and achieving its missions and visions depend primarily on its academic staffs' level of organizational commitment.

Altbach (2006) explained that academic staffs are key players to the successful accomplishment of the mission, goals and responsibilities mandated to higher education institutions. Jafri (2010) further support the idea indicating that staffs with strong commitment have an active curiosity, a passion for learning, a willingness to challenge the status quo and an eagerness to experiment with new methods and strategies.

The study revealed that there is a moderate level overall organizational commitment of academic staff, and the result also showed that a moderate level for each of the three dis-aggregated organizational commitment dimensions of affective, continuance and normative.

The study result support the study result by Alemu (2014) at Adama Science and Technology University which indicated that teachers had moderate level of organizational commitment. The present study further indicated that the academic staff exerts less effort and less willing to continue with and work for the success of the university. This 
result however contradicts with Madsen, Miller and John (2005), Yiing and Ahmad (2009), as well as Cunningham (2012) who explained that committed employees have a strong belief in and acceptance of the institutional goals and values, show a willingness to exert considerable effort on behalf of the institution, and are loyal to it.

In addition, the study result differs from the study by Welty, Burton and Wells (2014) which shows higher level of organizational commitment by staffs who wish to stay and contribute positively to the institution. The study revealed that there were factors which influence academic staffs' organizational commitment including toxic work environment, troubling work culture, reluctance leadership decision behaviors, lack of proper incentives, encouragements and compensation, personal characteristics, personality, shortage of capacity building training, task orientation, organizational justice, lack of accessible facility, feelings, interest, nature of work, low attitude and motivation intelligent, creativity; relationship with colleague, trustworthiness, loyalty, insecure political condition of the country and senses of ownership to the organization.

A study on determinants of commitment by Salami and Omole (2005) similarly indicated that commitment is a function of factors like motivation, participative decision making, organizational support, financial reward, communication, promotion prospects and leadership styles. As Riggio (2009) explained issues such as nature of work, job autonomy, the nature of job responsibility, the nature of social relationship at work, rewards and remunerations, and the opportunities for promotion and career advancements in the institution affects employees' organizational commitment.

The result of the present study also indicates some similar factors of commitment listed in studies by Tesfaye (2004) and Alemu (2014) such as lack of incentives/promotion, lack of proper care for academic staff, lack of teaching resources and office facilities, salary adequacy, and perceived quality of leader as predictors of commitment.

The study result arguably contradicts with studies by Brown and Sargeant (2007), which found several factors like, physiological contracts; gender and race determine the levels of organizational commitment significantly.

\subsection{Gender Differences in Academic Staffs' Level of Organizational Commitment}

This study clearly, revealed that gender has no effect in levels of commitment among academic staffs of the university. This result also supports the evidence that there was no significant difference between male and female high school teachers on organizational commitment (Teferi, Bekalu \& Abebe, 2016) except the setting. Contrary to this study, Mowday et al. (1982) stated that women may place greater value on their institutions and jobs than do their male counterparts since they have had to overcome more barriers to attain their positions in institutions.

\subsection{Differences of Organizational Commitment in reference to Level of Education}

In this regard, the result of a one-way MANOVA test in the study revealed that there is no significant difference among academic staffs' in the three dis-aggregated commitment dimensions (affective, continuance and normative). This supports the idea given by Mottaz (1988) which states that education has little effect on organizational commitment as well as the ideas by Teferi, Bekalu and Abebe (2016) that level of education does not significantly determine teachers' level of organizational commitment at high school level except the difference in setting only.

However, the study revealed that there was a statistically significant difference in academic staffs' overall organizational commitment with reference to level of education. Thus, academic staffs that have a bachelor's degree are more committed than who have master's degree.

This result is partly consistent with study results that showed the higher employees' level of education with the lower the level of organizational commitment. For example, some researches, (Mowday, R. T. Porter, L. W. and Steers, 1982) indicate an inverse relationship between institutional commitment and an individual's level of education

However, this study contradicts with the study of Teklle and Solomon (2016) at Arba Minch University which revealed that employees with higher educational qualification show more commitment than the employees with lower educational qualification. This contradiction is because there is no significant difference between academic staffs' who have bachelor degree and who have $\mathrm{PhD}$ and above as well as between those who have masters and $\mathrm{PhD}$ degrees in the current study.

\section{Conclusion and Recommendations}

The study assessed the level of academic staff organizational commitment in higher education institution with particular reference to Haramaya University. The study concludes that there is moderate level of organizational commitment among academic staff of the university. With this level of commitment, it is less likely to attain both personal performance objectives and organizational missions and vision of the university. 
Determinant factors in lowering the organizational commitment of the academic staff of the university were found to be leadership behavior (the qualities, traits and behavior of the leaders), lack of proper incentives, acknowledgment and compensation, work environment, personal characteristics, personality, shortage of capacity building training, task orientation, organizational justice, lack of accessible facility, feelings, interests, nature of work, low attitude and motivation, intelligence, creativity; relationship with colleagues, trustworthiness, loyalty, insecure political condition in the country, and diminished senses of ownership to the organization/University.

It is also possible to conclude that there was no statistically significant difference in academic staff commitment dimensions with reference to their gender and partly in their level of education.

However, unlike gender, level of education has some effect in overall commitment of academic staff in Haramaya University. Based on the findings, the study forwarded the following recommendations to improve the level of academic staff organizational commitment and to bring about organizational success.

$>$ Some of the university guiding principles and existing toxic working environment should be reviewed so as to enhance the organizational commitment of academic staff for achieving better university work performance.

$>$ Psycho-social support and guidance should be given to staff members to adjust and create a link between their organizational behavior and increase their loyalty, attachment, job security, creativity, personality and intelligence towards the holistic development of the institution with the increase of their work performance benefits.

$>$ An intensive effort needs to be made to help staff members discern what is expected of them, the kind of decision they should make for the success of university vision and missions through repeated consultation and supervision.

$>$ Academic staff creativity, sense of organizational ownership, attitude, and motivation towards the performance of organizational goal should be given due attention not only by the university but also by other stakeholders including the Ministry of Education.

$>$ Conducive work environment and organizational culture should be rebuilt and the academic staff should be given due attention through acknowledgment, compensation, and incentive packages towards their good performance in a stainable way.

$>$ Project and research works that contribute to the excellence of the university and the development of the academic staff in their education, social and economic development benefits need to be designed and implemented.

$>$ Clear communication and research-based task orientation as well as continuous professional training must be regularly given to academic staff with responsibility towards improvement of both personal and organizational work performance in addressing organizational objectives.

$>$ Academic staff should engage in short and long term plan-oriented university achievement goals to accomplish them cooperatively and effectively.

\section{References}

Altbach, P. G. (2006). Comparative higher education: Knowledge and development. Boston: Boston College.

Alemu, D. (2014). Looking at Human Element in Education: Organizational Commitment and Job Satisfaction of Teachers at Adama Science and Technology University, Browsing "SMU Conference Proceedings.

Allen, N.J. \& Meyer, J.P. (1990). The measurement and antecedents of affective, continuance and normative commitment to the organization. Journal of Occupational Psychology, 63, 1-18. https://doi.org/10.1111/j.2044-8325.1990.tb00506.x

Allen, N.J. \& Meyer, J.P. (1991). A Three-Component Conceptualization of Organizational Commitment. Human Resources Management Review, 1, 61-89. https://doi.org/10.1016/1053-4822(91)90011-Z

Allen, N.J. \& Meyer, J.P. (1996). Affective, continuance, and normative commitment to the organization: an examination of construct validity. Journal of Vocational Behavior, 49, 252-276.

Bin Dost,M., Ahmed, D.Z., Shafi, N., \& Shaheen,W.A. (2011). Impact of employee commitment on organizational performance Arabian Journal of Business and Management Review, 1(3), 87-98 retrieved on 23-06-2015 from http://www.arabianjbmr.com/pdfs /OM_VOL_1_(3)/8.pdf.

Briner, R. B. (2000). Relationships between work environments, psychological environments and psychological 
well-being: in-depth review. Occup. Med., 50(5), 299-303. https://doi.org/10.1093/occmed/50.5.299

Brown, D. \& Sargeant, M.A. (2007). Job satisfaction, organizational commitment, and religious commitment of full-time university employees. Journal of Research on Christian Education, 16, 211-241. https://doi.org/10.1080/10656210701647613

Chartered Institute of Personnel Development, (2014). Strategic reward and total reward. Factsheet. March. London, Chartered Institute of Personnel and Development. Online. Available at http://www.cipd.co.uk/hr-resources/factsheets/strategic-reward-total reward.aspx.

Chughtai, A.A. \& Zafar, S. (2006). Antecedents and consequences of organizational commitment among Pakistani university teachers. Applied Human Resources Management Research, 11(1), 39-64.

Cohen, A. (1993). Age and tenure in relation to organizational commitment: A meta-analysis. Basic and Applied Social Psychology, 14, 143-159. https://doi.org/10.1207/s15324834basp1402_2

Cohen, A. (2007). Dynamics between occupational and organizational commitment in the context of flexible labor markets: A review of literature and suggestions for a future research agenda. Bremen: Institut Technik und Bildung, UniversitŠt Bremen.

Cunningham, G.B. (2012). The relationships among commitment to change, coping with change, and turnover intentions. European Journal of Work and Organisational Psychology, 15(1), 29-45. https://doi.org/10.1080/13594320500418766

Curtis, S. \& Wright, D. (2001). Retaining employees - the fast track to commitment. Management Research News, 24(8), 59-64. https://doi.org/10.1108/01409170110782964

Dixit, V., \& Bhati, M. (2012). A study about employee commitment and its impact on sustained productivity in Indian auto-component industry. European Journal of Business and Social Sciences, 1(6), 34-51.

Fiorita, J. A., Bozeman, D. P., Young, A., Meurs, J. A. (2007). Organization Commitment, Human Resource Practices, and Organization Characteristic. Journal of Managerial Issues 19(2), 186207.

Huselid, A.M. (1995). The impact of human resource management practices on turnover, productivity, and corporate financial performance. Academy of Management Journal, 38(1), 635-672. https://doi.org/10.2307/256741

Ifeoma, L.G. \& Iliya, A. (2015) Assessment of teacher motivation in less developed countries. Journal of Education and Practice, 6(22), 10-17. Available at: http://eric.ed.gov/?id=EJ1079453[Accessed 18 January, 2019].

Jafri, M.H. (2010). Organisational commitment and employee's innovative behavior. Journal of Management Research, 10(1), 62-68.

Jans, N.A. (1989). Organizational commitment, career factors, and career/life stage. Journal of Organizational Behavior, 10(3), 247-266. https://doi.org/10.1002/job.4030100305

Lamba, S., \& Choudhary, N. (2013). Impact of HRM practices on organizational commitment of employees. International Journal of Advancements in Research and Technology, 2(4), 407-423.

Madsen, S.R. Miller, D. \& John, C.R. (2005). Readiness for organizational change: Do organizational commitment and social relationships in the workplace make a difference? Human Resource Development, 16(2), 213-233. https://doi.org/10.1002/hrdq.1134

Meyer, J.P. \& Allen, N.J. (1984). Testing the side bet theory of organizational commitment: Some methodological considerations. Journal of Applied Psychology, 69, 372-378. https://doi.org/10.1037//0021-9010.69.3.372

Meyer, J.P. \& Allen, J.N. (1997). Commitment in the Workplace Theory, research and application. Sage Publications, Thousand Oaks, CA.

Meyer, J. P., Stanley, D. J., Herscovitch, L., \& Topolnytsky, L. (2002). Affective, continuance, and normative commitment to the organization: A meta-analysis of antecedents, correlates, and consequences. Journal of Vocational Behavior, 61, 20. https://doi.org/10.1006/jvbe.2001.1842

Mohammed, F. \& Eleswed, M. (2013). Job satisfaction and organizational commitment: A correlation study in Bahrain. Research. Journal of Business, Humanities and Technology, 3(5), 43-53.

Mohamed, G. (2013), Job satisfaction and organizational commitment of teacher educators: The case of Arbaminch College of Teacher Education. Unpublished thesis work.

Mottaz, C. J. (1988). Determinant of commitment. Human Relations, 41(6), 467-482. https://doi.org/10.1177/001872678804100604 
Mowday, R. T. Porter, L. W. \& Steers, R. (1982). Organizational Linkages, psychology of commitment, Absenteeism and Turn Over. San Diego, CA: Academic Press.

Nunnally, J.C. \& Bernstein, I.H. (1994). Psychometric Theory. (3rd edn.). New York: McGraw Hill.

Ogaboh, A. A. M., Nkpoyen F. \& Ushie, E. M. (2010). Career development and employee commitment in industrial organizations in Calabar, Nigeria: American Journal of Scientific and Industrial Re-search, 1(2). https://doi.org/10.5251/ajsir.2010.1.2.105.114

Oludeyi,O.S. (2015). Workplace factors as determinants of job commitment among senior non-teaching staff of Olabisi Onabanjo University, Ogun State. Master's Thesis of the Department of Adult Education, the University of Ibadan, Oyo State, Nigeria.

Peters, T.J., \& Waterman, R.H. (1982). In search of excellence. New York: Harpers and Row.

Riggio, R.E. (2009). Introduction to industrial/organizational psychology. London: Pearson.

Salami, S.O. \& Omole, O.A. (2005). Participation in decision making process, Incentives and training as predictors of organizational commitment among industrial workers. African Journal of Psychological Study of social issues, $8(2), 210-227$.

Samad, S. (2011). The effects of job satisfaction on organizational commitment and job performance relationship: A case of managers in Malaysia`s Manufacturing Companies. European Journal of Social Sciences, 18.

SamGnanakkan, S. (2010). Mediating role of organizational commitment on HR practices and turnover intention among ICT professionals. Journal of Management Research, 10(1), 39-61.

Solomon, O., Hashim, N.H., Mehdi, Z.B., \& Ajagbe, M.U. (2012). Employee motivation and organizational performance in multinational companies: astudy of Cadbury Nigeria Plc. International Journal of Research in Management \& Technology, 2(3), 303-312.

Stallworth, L. (2004). Antecedents and consequence of organizational commitment to accounting organizations. Managerial Auditing Journal, 19(7), 945-955. https://doi.org/10.1108/02686900410549457

Teferi, G., Bekalu, F \& Abebe, H (2016). Teacher's job satisfaction and its relationship with organizational Commitment in Ethiopian primary schools of Bonga town. European Scientific Journal, 13(12), 1857 - 7881. https://doi.org/10.19044/esj.2016.v12n13p380

Teklle, A. \& Solomon, M. (2016). The Relationship between job satisfaction and organizational commitment in public higher education institution: The Case of Arba Minch University, Ethiopia.

Tetty, W.J. (2006). Staff retention in African Universities: Elements of sustainable strategy. Commissioned by the World Bank: Washington DC.

Tesfaye Semela. (2004). Perceptions of Work Environment in Ethiopian Higher Learning Institutions: A Search for Antecedents of Organizational Commitment and Turnover among Debub University Instructors. The Ethiopian Journal of Higher Education, 1(2)

Viljoen, J.P. \& Rothmann, S. (2009). Occupational stress, ill health and organizational commitment of employees at a University of Technology. South African Journal of Industrial Psychology, 35, 1-11. https://doi.org/10.4102/sajip.v35i1.730

Welty, J., Burton, L., \& Wells, J.E. (2014). Examining the influence of transformational leadership, leader-member exchange, organisational commitment, job embeddedness and job search on turnover intentions of Division I senior administrators. Leadership \& Organizational Development Journal, 35(8), 740-755. https://doi.org/10.1108/LODJ10-2012-0128

Witt, C. A. \& Steward. (1996). Solicitors and Customer Care. The Services Industries Journal, 6, 21-34. https://doi.org/10.1080/02642069600000003

Yamane, Yaro. (1964). Statistics: An introductory analysis. New York: Hamper.

Yiing, L. H. \& Ahmad, K.Z.B. (2009). The moderating effects of organizational culture on the relationships between leadership behavior and organizational commitment and between organizational commitment and job satisfaction and performance. Leadership and Organization Development Journal, 30(1), 53-86. https://doi.org/10.1108/01437730910927106

Yusuf N. \& Metiboba S. (2012). Work environment and job attitude among employees in a Nigerian work organization. Journal of Sustainable Society, 1(2), 36-43. 